\title{
A CONTRIBUIÇÃO DA EMPRESA PARA A CRISE PENITENCIÁRIA
}

\author{
Luis Otavio Sales da Silva Junior ${ }^{1}$ \\ Mateus Eduardo Siqueira Nunes Bertoncini ${ }^{2}$
}

\section{RESUMO:}

O presente artigo objetiva examinar em que medida a sociedade civil, por meio da empresa, pode contribuir para o abrandamento da crise do sistema carcerário brasileiro. $\mathrm{O}$ estudo, pautado no método dedutivo, trata da função social da empresa e do incentivo ao trabalho do preso, na senda de colaborar para a redução da violência e da reincidência. Sem confundi-lo com panaceia para o quadro agudo de violência e desordem carcerária, o trabalho visa a discutir a ressocialização e o resgate da dignidade da pessoa do condenado, por meio de sanções positivas, patrocinadas por políticas públicas.

Palavras-chave: Crise do sistema carcerário; função social da empresa; sanções positivas; o trabalho do preso; ressocialização

\section{THE COMPANY'S CONTRIBUTION TO THE PENITENTIARY CRISIS}

\begin{abstract}
:
This article aims the examination on how society, through Companies, can contribute on easing the crisis on the Brazilian prison system, especially by increasing the job offers to prisoners. The study, based on the deductive method, explains the social duties of Companies and the incentive to prisoners' work as a contribution on reducing violence and recidivism. Without confusing this with panacea for the harsh situation of violence and prisons disorder. If prisoners get employed this would help to rescue their dignity, as a different manner to deal with punishment through public policies.
\end{abstract}

Keywords: Penitentiary crisis; social function of the company; the right to work of prisoners; re-socialization

\section{INTRODUÇÃO}

Winston Churchill, em meados de 1910, ocupando ainda um cargo ministerial responsável pela segurança da Inglaterra afirmou: "a moderação e o estado de espírito do povo quanto ao tratamento dado ao crime e aos criminosos são uma das provas mais irrefutáveis da civilidade de uma nação"1. Enquanto as boas condições humanas no cárcere

\footnotetext{
${ }^{1}$ Mestrando em Direito Empresarial e Cidadania pelo Centro Universitário Curitiba (UNICURITIBA). Especialista em Direito Penal e Criminologia pelo Instituto de Criminologia e Política Criminal (ICPC). Advogado.luisotavio@dotti.adv.br

${ }^{2}$ Doutor em Direito do Estado pela UFPR. Pós-Doutor em Direito pela UFSC. Professor do Programa de Mestrado em Direito do Centro Universitário Curitiba (UNICURITIBA). Procurador de Justiça do Ministério Público do Estado do Paraná.
} 
forem consideradas privilégio ou prêmio à bandidagem, não haverá saída para a tragédia penitenciária. O caos nas prisões brasileiras é tão antigo quanto a previsão da primeira Constituição, de 1824, que dispunha (art. 179, XXI) que as cadeias "serão seguras, limpas, bem arejadas, havendo diversas casas para separação dos réus, conforme suas circunstâncias e a natureza dos seus crimes. Desde já ficam abolidos os açoites, a tortura, a marca de ferro quente, e todas as penas cruéis".2

Além da histórica debilidade do sistema, retratada em problemas de saneamento e higiene, superlotação e falta de espaço, marginalização e ausência de perspectiva de futuro, as prisões brasileiras funcionam como trincheiras de facções criminosa, que arregimentam presos com promessas de assistência à família, proteção, privilégios e poder, ou simplesmente pela disseminação do medo. Com isso, o efeito gerado é justamente o inverso do ideal de ressocialização. Somem-se a isso os episódios recorrentes de barbárie nas prisões, com chacinas mórbidas e brutais entre grupos rivais.

Sem considerá-lo a panaceia para esse quadro agudo de violência e desordem, o incentivo ao trabalho dos presos, com a participação ativa da sociedade civil através das empresas, pode oferecer uma esperança de redução da violência e da reincidência. Convém promover a discussão de ações coordenadas entre os três Poderes para aumentar a integração entre comunidade e o sistema penitenciário.

Nessa perspectiva, o problema central da pesquisa reside na forma como o Estado e o setor privado podem interagir para que aquele cumpra com o seu papel de ressocialização do apenado e este cumpra com a função social que a Constituição de 1988 lhe atribuiu no capítulo da Ordem Econômica.

A relevância do tema parece evidente. O problema carcerário, além de atual, é de um peso significativo para toda a comunidade, haja vista as múltiplas violações de direitos humanos que compreende e que vão muito além da execução da pena e do trabalho do preso ou egresso. O método de abordagem que se empregará será o dedutivo-dialético, a partir de pesquisa bibliográfica e de levantamento de dados, a princípio, capaz de oferecer o instrumental necessário para se iniciar uma resposta cuja complexidade ultrapassa, evidentemente, as estreitas divisas de um artigo científico, destinado a tisnar um problema nacional, cuja dimensão exigiria para além de profunda pesquisa de campo, a análise de experiências locais e estrangeiras típicas de um estudo acadêmico de maior alento. 


\section{CONDIÇÕES GERAIS DO SISTEMA PENITENCIÁRIO BRASILEIRO}

Segundo informações divulgadas pelo Ministério da Justiça no final de 2014, o Brasil, com seus mais de 700.000 presos, tem a terceira maior população carcerária do mundo em termos absolutos (computadas as prisões domiciliares), atrás apenas dos Estados Unidos (2,2 milhões) e da China (1,6 milhão) ${ }^{3}$. Dados do Levantamento Nacional de Informações Penitenciárias - Infopen, divulgados naquele ano, revelam que o número de pessoas presas no Brasil aumentou mais de $400 \%$ em 20 anos, alcançando o total de 711.463 detidos no ano da publicação do estudo (a população brasileira, em contrapartida, aumentou apenas 36\% no mesmo período). O aumento constante da população carcerária (em torno de $7 \%$ ao ano, aproximadamente ${ }^{4}$ ) é agravado pelo déficit de vagas no sistema, estimado, no ano de 2014, em 354.244 - computadas, no cálculo, as prisões domiciliares. ${ }^{5}$ O Paraná, um dos estados com situação um pouco menos vergonhosa, contava então com uma população carcerária de 28.309 e um déficit de vagas de 4.627. Vê-se, assim, que a capacidade do sistema prisional nacional está longe de comportar o total de condenados presos (isso sem contar os mandados de prisão em aberto), o que potencializa as condições precárias e sub-humanas dos presídios, conhecidos pela "falta de espaço, de higiene, doenças em série, profissionais mal treinados e corrupção". 6

Embora os números revelem em boa medida a situação carcerária brasileira pouco engrandecedora (que fazem terra arrasada, sob o viés jurídico, ao princípio da excepcionalidade da prisão), o quadro é agravado pelo fato de que nem mesmo com um alto nível de encarceramento abrandou-se o problema da violência. Ao contrário, "o cárcere tem reforçado mecanismos de reprodução de um ciclo vicioso de violência que, como padrão, envolve a vulnerabilidade, o crime, a prisão e a reincidência e, por vezes, serve de combustível para facções criminosas", conforme registrara o relatório do Infopen de 2014, que ainda vaticinou: “o encarceramento é o grande bálsamo para os males da segurança pública."7

O Conselho Nacional de Justiça (CNJ) oficialmente sustenta que o modelo prisional brasileiro "alimenta um ciclo de violências que se projeta para toda a sociedade, reforçado por uma ambiência degradante em estabelecimentos que pouco ou minimamente estimulam qualquer proposta de transformação daqueles que ali estão."8 
O Departamento de Monitoramento e Fiscalização do Sistema Carcerário e do Sistema de Execução de Medidas Socioeducativas - DMF, vinculado ao CNJ, desenvolve desde 2008 o programa Mutirão Carcerário, por meio do qual juízes percorrem os Estados-membros inspecionando estabelecimentos prisionais e as condições de acomodação dos detentos. ${ }^{9}$ Em um amplo estudo designado "raio-x do sistema penitenciário brasileiro", divulgado em $2012^{10}$, o DMF registrou em fotografias a nefasta e angustiante realidade do cárcere nacional com um diagnóstico específico para cada região do país (norte, nordeste, centro-oeste, sudeste e sul). Quanto ao sul, acusou-se uma "realidade diferente da ideia de Sul que existe no imaginário popular brasileiro: uma sociedade próspera e livre dos problemas que afetam o resto do Brasil." "11 Especificamente quanto ao Paraná, as diligências do Mutirão revelaram que, em 2010, 15,8 mil pessoas detidas em carceragens de delegacias, cadeias públicas ou centros de triagem do Estado estavam "amontoadas em celas, onde deveriam permanecer por no máximo 24 horas", amargando "o gélido inverno paranaense coando o café nas próprias meias." 12

Na apresentação desse documento, o então Presidente do Supremo Tribunal Federal, ex-Ministro Cezar Peluso, definiu como "perversa" a realidade prisional brasileira e convocou todos os setores da sociedade a se engajar pela "reabilitação e reinserção" dos apenados, para que não se perpetue uma situação

[...] em que pessoas que cumprem condenações perdem, não apenas a liberdade, mas, sobretudo, as perspectivas de retomada de vida condigna e socialmente útil, quando a Constituição da República convida todos a construir uma sociedade justa e solidária, enraizada no respeito à dignidade da pessoa humana. ${ }^{13}$

Esses estudos empíricos conduzidos pelo CNJ confirmam o que a doutrina pátria já alertava há um algum tempo sobre o antagonismo entre os ideais contemplados na lei e a realidade cotidiana das penas e medidas de segurança.

Dotti atribui à crise do dogmatismo boa parte desse contraste entre o direito e a realidade da execução penal, pontuando, por exemplo, o conformismo das proclamações retóricas de "recuperação, ressocialização, readaptação, reinserção ou reeducação social, [...] sem que a execução prática das medidas corresponda aos anseios de recuperação que não raramente se exaurem na literalidade dos textos." ${ }^{14}$ Citando Elías Neuman, Dotti coloca que a readaptação social do delinquente "é uma das expressões que conquistaram fácil trânsito 
jurídico e está apoiada sobre um consenso", mas que, na verdade, é “una de las muletillas legales más vacias de contenido". ${ }^{15}$ E conclui

A prisionalização é terapia de choque permanente, cuja natureza e extensão jamais poderiam autorizar a tese enfadonha de que constitui uma etapa para a liberdade, assim como se fosse possível sustentar o paradoxo de preparar alguém para disputar uma prova de corrida, amarrando-o a uma cama. ${ }^{16}$

Heleno Fragoso argutamente denunciou as "discrepâncias entre a ciência e a experiência":

\begin{abstract}
Elaboramos um belo sistema de direito penal e, afinal, ele serve para quê? Como funciona efetivamente? A análise crítica do próprio sistema e as incongruências entre a elaboração teórica e a prática vieram levar os juristas a uma visão mais humilde de sua atividade e a graves dúvidas sobre as virtualidades do magistério punitivo do Estado. ${ }^{17}$
\end{abstract}

O esgotamento do sistema reclama, além de um repensar quanto às respostas penais tradicionais, um olhar para alternativas na execução da pena que desafoguem os estabelecimentos prisionais com superlotação aguda e deem efetividade aos fins da punição conjugados com os valores constitucionais que colocam a pessoa humana no centro do sistema. O tratamento digno e respeitoso para a regeneração da vida dos presos não se deve apenas a ditames jurídico-normativos, mas a uma atitude racional e humanista frente ao fato de que um dia aqueles haverão de estar novamente entre nós.

A exposição de motivos da Lei no 7.210/84 (Lei de Execução Penal - LEP), em seu tópico 22, reproduz a lição de Hilde Kaufman acerca do imperativo de uma execução penal humanizada, fixando o propósito cardeal do diploma que então passaria a viger

\footnotetext{
la ejecución penal humanizada no solo no pone em peligro la seguridade y el ordem estatal, sino todo lo contrario. Mientras la ejecución penal humanizada es um apoyo del ordem y la seguridade estatal, uma ejecución penal deshumanizada atenta precisamente contra la seguridade estatal. ${ }^{18}$
}

O presente estudo enfoca o trabalho como mecanismo central de reinserção social dos condenados, na medida em que fornece uma perspectiva real de futuro digno após a restituição da liberdade - o egresso com experiência laboral pretérita positiva possui maiores chances de se recolocar no mercado de trabalho, ou mesmo de continuar na empresa que o admitiu quando ainda cumpria pena. A sociedade há de lidar com o fato de que presidiários 
um dia retornam à vida em liberdade. As empresas, cujo funcionamento é legítimo apenas quando atrelado à função social, têm papel fundamental na mudança da realidade do cárcere, pois podem oferecer ocupação a quem, privado de liberdade, encontra-se esquecido em um ambiente de embrutecimento e de anulação da dignidade e da personalidade. O desenvolvimento de programas de disponibilização de emprego para presidiários como política de Estado vai ao encontro, inclusive, dos interesses econômicos da empresa como entidade produtiva e do poder público, ante a ampliação do mercado formal, redução da reincidência, desigualdades e, possivelmente, da violência.

\section{O DIREITO AO TRABALHO DO CONDENADO}

O Primeiro Congresso das Nações Unidas sobre Prevenção do Crime e Tratamento de Delinquentes, realizado em Genebra em 1955, propôs um conjunto de Regras Mínimas para o Tratamento dos Reclusos. E previu, no item 7.1, o direito ao trabalho, que "deve ser de natureza que mantenha ou aumente as capacidades dos reclusos para ganharem honestamente a vida depois de libertados".

A Resolução n ${ }^{\circ}$ 14/94 do Conselho Nacional de Política Criminal e Penitenciária CNPCP, inspirada no documento das Nações Unidas, fixou as Regras Mínimas para o Tratamento do Preso no Brasil, contemplando o direito ao trabalho no art. 56, cujo inciso III estabelece que "será proporcionado ao condenado trabalho educativo e produtivo" 19 . Em maio de 2015, as Nações Unidas revisaram as regras da década de 50, oficializando um novo conjunto de normas designado Regras de Mandela com a participação ativa do Brasil. O CNJ divulgou recentemente esse documento com a recomendação de que suas regras fossem observadas para "transformarem o paradigma de encarceramento praticado pela justiça brasileira" ${ }^{20}$. No tópico referente ao trabalho, consta a regra 98, segundo a qual "quando possível, o trabalho realizado deve manter ou aumentar a habilidade dos presos para que possam viver de maneira digna após sua liberação".

Como se infere, a ocupação laboral de presidiários é tema que recebe atenção permanente de organismos internacionais, por ser um corolário do direito fundamental ao cumprimento de pena em condições dignas. Na lição de Fabio Comparato, o fundamento dos direitos humanos transcende a previsão no Direito interno da organização estatal por 
corresponder ao que o autor designa "consciência ética coletiva", que representa a “convicção, longa e largamente estabelecida na comunidade, de que a dignidade da condição humana exige o respeito a certos bens ou valores em qualquer circunstância", em expansão no curso da História. ${ }^{21}$

Não obstante o quadro normativo internacional, há previsão suficiente quanto ao tema no âmbito do Direito doméstico brasileiro. A Constituição Federal considera o trabalho a base da ordem social (art. 193) e sua livre escolha um direito fundamental (art. 5, XIII). A execução penal tem como objetivo principal declarado propiciar o retorno do condenado ao convívio em sociedade. A Lei no 7.210/84 (Lei de Execução Penal - LEP), em seu art. 1º, prevê como finalidade do cumprimento de pena a "harmônica integração social do condenado". Há outros dispositivos na LEP inspirados no ideal de ressocialização, dentre os quais o art. 10, que dispõe sobre o serviço de assistência ao preso "objetivando prevenir o crime e orientar o retorno à convivência em sociedade"; o art. 28, que trata o trabalho como "dever social e condição de dignidade humana" com "finalidade educativa e produtiva"; e o art. 122, que concede autorização para saída temporária de condenados a regime semiaberto para "participação em atividades que concorram para o retorno ao convívio social".

O encarceramento não pode significar a anulação do direito ao trabalho, que deve ser preservado nas condições em que a lei determinar conforme os imperativos de segurança. $\mathrm{O}$ estado de prisão, portanto, não deve inviabilizar, por si só, o direito ao trabalho, especialmente porque o cumprimento de pena privativa de liberdade não visa a tornar inócuo o indivíduo em sua dimensão moral e ética. Por outro lado, o trabalho é um fator socializante inegável. Em interessante abordagem, Francisco Cardozo Oliveira e Osni de Jesus Taborda Ribas reconhecem que o trabalho do preso não corresponde a simples "complemento da pena", tampouco se esgota em força produtiva; trata-se de uma via para o "acesso a direitos", permitindo que o preso seja "considerado pessoa capaz de direitos, de estima, consideração e respeito". 22

Os tópicos 56 e 57 da exposição de motivos da LEP referem o trabalho dos condenados presos como elemento de redução das "diferenças entre a vida nas prisões e a vida em liberdade", e o define "como dever social e condição de dignidade humana" com dupla finalidade: "educativa e produtiva". ${ }^{23}$ Mir Puig define a ressocialização como a "criação de possibilidades de participação nos sistemas sociais", cujo resultado seja um "processo de interação" permanente entre o infrator e o Estado 
aquél no debe ser tratado como puro objeto de um proceso de "condicción" del Estado social, sino como sujeito de un proceso de "regulación" y de aprendizage, proceso que debe tender no solo a la adaptación a las normas dominantes, sino a elaborar, en un proceso de interación, alternativas as la conducta criminal, y, com ello, a la participación en las relaciones da vida social. ${ }^{24}$

A ocupação laboral tem papel fundamental no processo de ressocialização. Por meio da profissionalização do preso incutem-se hábitos laborais que aceleram o ideal de readaptação social, especialmente no contexto de um ambiente pernicioso, promotor de desvios sociais. Miguel Reale Júnior aduz que o trabalho representa a "espinha dorsal da execução da pena privativa de liberdade" e acrescenta que a ociosidade representa "um desespero, não só por falta do salário essencial, mas também por não se ter o que fazer, mal do qual sofre os aposentados, maior ainda é a aflição do preso, já destituído de todos os demais papéis sociais". ${ }^{25}$ Nas palavras do autor:

\begin{abstract}
O homem constitui um feixe de sentimentos, pensamentos e ações, na verdade, define-se por aquilo que faz. A primeira coisa que se pergunta a um desconhecido é sobre o que ele faz, como forma essencial de passar a conhecê-lo, cientificando-se do seu universo. [...] $\mathrm{O}$ trabalho fixa o horizonte da pessoa, a coloca no mundo social, a situa na sociedade. O trabalho para o homem preso é tanto ou mais importante do que para o homem livre, pois é necessário para sua higidez mental e condição de dignidade humana, [...] imprescindível para fazer o tempo perdido passar e assim não ser tão perdido. Ademais, o trabalho, sendo remunerado, ajuda a formar um pecúlio, a auxiliar a família, e a obter uma colocação ao ganhar a liberdade condicional. ${ }^{26}$
\end{abstract}

O art. 41, da LEP, define como direito do preso a "atribuição de trabalho e sua remuneração", enquanto os artigos 36 e 37 disciplinam o trabalho externo. O condenado a regime fechado deve ter cumprido no mínimo $1 / 6$ da pena para obter o direito ao trabalho externo, enquanto os apenados em regime semiaberto e aberto possuem essa prerrogativa independentemente do cumprimento desse requisito. ${ }^{27} \mathrm{O}$ preso em regime fechado se sujeita, em regra, a trabalho dentro da penitenciária, mas poderá realizar trabalho externo (caso assim consinta e cumpra com o requisito temporal já referido) em serviço ou obras públicas realizadas por órgãos da Administração Direta ou Indireta, ou entidades privadas, desde que tomadas as cautelas contra a fuga e em favor da disciplina (art. 36). O limite máximo do número de presos será de $10 \%$ do total de empregados na obra $\left(\S 1^{\circ}\right)$. Ao preso em regime semiaberto é admitido o trabalho externo sob vigilância, bem como a frequência a cursos 
supletivos profissionalizantes, de instrução de ensino médio ou superior. Por fim, ao condenado em regime aberto o trabalho é sempre externo. Durante o dia, o condenado deve trabalhar, frequentar cursos ou realizar outras atividades autorizadas, fora do estabelecimento e sem vigilância. Durante o período noturno e nos dias de folga, permanece recolhido na Casa do Albergado.

Dentre as vantagens ao preso em razão da submissão ao trabalho, há uma mais imediata e objetiva do que eventual aumento do senso de disciplina, do sentimento próprio de utilidade ou reinserção social, todas de conotação subjetiva. Trata-se do instituto da remição, que consiste no abatimento do tempo de pena do condenado em regime fechado ou semiaberto por trabalho ou estudo - para cada 3 dias de trabalho, abate-se 1 dia de pena (art. $\left.126, \S 1^{\circ}, \mathrm{II}\right)$. Ou seja, há a vantagem objetiva e concreta de abreviação da pena pelo trabalho.

Como é direito fundamental do preso a proibição de trabalhos forçados ou obrigatórios (CF, art. 5 XLVII, c), o art. 29, §1 , da LEP, e o art. 39, do Código Penal, instituem o dever de remuneração do trabalhador encarcerado. Porém, segundo o art. $28, \S 2^{\circ}$, o trabalho do preso "não está sujeito ao regime da Consolidação das Leis do Trabalho". Isso significa que a empresa contratante fica isenta de alguns encargos trabalhistas, como férias, $13^{\circ} \mathrm{e}$ recolhimento ao FGTS, o que determina um custo três vezes menor em relação à contratação conforme a CLT, consoante informação do portal do Conselho Nacional de Justiça. ${ }^{28}$ Há, porém, quem entenda que a não sujeição à CLT enseja a precarização da relação de trabalho do presidiário. ${ }^{29}$ Não obstante as objeções, deve-se ponderar que é preferível a oferta de trabalho em condições possivelmente ainda não ideais do que a inexistência mesma de oportunidade. Sob o ponto de vista econômico, caso não haja diferencial algum entre a oferta de mão de obra de empregado livre e do empregado encarcerado, somente por abnegação o empregador optaria pela segunda opção. Embora passível de críticas o diferencial consubstanciado na supressão de alguns direitos trabalhistas, é um aspecto apto a despertar o interesse do empresariado, especialmente pela considerável diminuição de custos com mão de obra.

De todo modo, há um regime jurídico próprio para o trabalho executado por presos. $\mathrm{O}$ Estado tem o dever de fiscalizar as condições e o efetivo cumprimento do trabalho extramuros (trabalho externo), além da prerrogativa de revogar o benefício nas hipóteses elencadas no parágrafo único do art. 37 da LEP. 
Além de facilitar a ressocialização, a inserção de presos no mercado de trabalho tem efeito sobre a reincidência criminal, impactando na coesão do tecido social: uma vez frustrado o objetivo de adaptação do encarcerado ao convívio em sociedade, cresce a marginalização e a violência. Como a maioria das pessoas presas é jovem $(55,07 \%$ da população encarcerada tem até 29 anos) ${ }^{30}$, o direito ao trabalho, a depender da extensão do seu exercício, pode ainda interferir no resultado produtivo do país.

O Departamento Penitenciário Nacional, órgão vinculado ao Ministério da Justiça, em seu Levantamento Nacional de Informações Penitenciárias - Infopen (dezembro de 2014), defendeu a definição de uma política penitenciária nacional para o enfrentamento dos problemas penitenciários nacionais, cujo eixo deveria ser a "potencialização das políticas de reintegração", dando-se prioridade às políticas de "educação, qualificação e trabalho prisional como uma ação de prevenção na área de segurança pública e uma acertada política de prevenção à reincidência". ${ }^{31}$ Conforme o art. 62, da Lei no 7.210/84, ao Conselho Nacional de Política Criminal e Penitenciária incumbe a avaliação periódica do sistema criminal "para sua adequação às necessidades do País" (art. 64, III). Em 2015, este órgão elaborou o Plano Nacional de Política Criminal (renovado a cada quatro anos) preconizando como diretriz de política carcerária o fortalecimento dos "mecanismos de integração social nos estabelecimentos prisionais, por meio da promoção do acesso [...] ao trabalho". ${ }^{32}$ Esse documento registra que "somente $16 \%$ das pessoas privadas de liberdade tem acesso ao trabalho", acusando a "reincidência recorrente". ${ }^{33}$ No tópico "medida 4: fortalecimento da política de integração social no sistema prisional" recomenda-se "incentivar fiscalmente as empresas que contratam presos e egressos", ao passo que no tópico "medida 10: egressos e política de reintegração social", propõe-se a instituição de medidas que "favoreçam a inserção dos egressos no mercado de trabalho". ${ }^{34}$

Como se depreende de julgados recentes dos Tribunais Superiores, o Poder Judiciário (ao menos na esfera federal) tem estimulado o trabalho no cárcere. Não somente por ação do Conselho Nacional de Justiça (CF, art. 92, I-A) no âmbito das políticas judiciárias, mas também na produção jurisprudencial, ao interpretar a lei de forma a ampliar o espectro de aplicação desse direito. O Supremo Tribunal Federal, ao julgar recurso cuidando do trabalho externo do preso em regime semiaberto, assentou: 
presos que se encontrem em regime inicial semiaberto. Diversos fundamentos se conjugam para a manutenção desse entendimento. 2. A aplicação do requisito temporal teria o efeito de esvaziar a possibilidade de trabalho externo por parte dos apenados em regime inicial semiaberto. Isso porque, após o cumprimento de 1/6 da pena, esses condenados estarão habilitados à progressão para o regime aberto, que tem no trabalho externo uma de suas características intrínsecas. 3. A interpretação jurídica não pode tratar a realidade fática com indiferença, menos ainda quando se trate de definir o regime de cumprimento das penas privativas de liberdade. No caso, são graves e notórias as deficiências do sistema prisional. Neste cenário, sem descurar dos deveres de proteção que o Estado tem para com a sociedade, as instituições devem prestigiar os entendimentos razoáveis que não sobrecarreguem ainda mais o sistema, nem tampouco imponham aos apenados situações mais gravosas do que as que decorrem da lei e das condenações que sofreram. $[\ldots]^{35}$

O Superior Tribunal de Justiça também tem estimulado o direito ao trabalho de encarcerados, como se depreende do Recurso Especial 1381315/RJ, em que a Corte firmou a tese em sede de recurso repetitivo de que é possível a remição de parte do tempo de execução da pena quando o condenado, em regime fechado ou semiaberto, desempenha atividade laborativa extramuros. Esse entendimento deu origem à Súmula 562: "É possível a remição de parte do tempo de execução da pena quando o condenado, em regime fechado ou semiaberto, desempenha atividade laborativa, ainda que extramuros. ${ }^{36}$ Vale dizer, não somente o trabalho executado dentro do presídio abate o tempo restante da condenação, mas também aquele realizado fora do ambiente carcerário, pois "a inteligência da Lei de Execução Penal direciona-se a premiar o apenado que demonstra esforço em se ressocializar e que busca, na atividade laboral, um incentivo maior à reintegração social". ${ }^{37}$

\section{A FUNÇÃO DO ESTADO}

Conquanto a importância da atuação da comunidade, o Estado tem papel essencial na criação de programas que facilitem o diálogo entre o mundo do cárcere e o mundo da liberdade. Não apenas com a criação de incentivos para o engajamento da iniciativa privada na criação de postos de trabalho a presidiários, mas com a liberação das amarras que mantêm os particulares na inércia. A criação de mecanismos para a efetivação do direito ao trabalho externo não significa, evidentemente, a "delegação do poder de punir na fase de execução da pena, que continuará a ser feita pelo órgão estatal competente (judiciário e administrativo), sempre inserido no regime cuja finalidade se dirige à reintegração social do condenado" 38 . Mirabete acrescenta, ainda, a cautela da "seleção cuidadosa dos presos [...] a fim de se 
evitarem problemas de fuga e indisciplina [...]. ${ }^{39}$ Trata-se, portanto, da atuação coordenada entre Estado e a sociedade civil, sobre a qual a administração mantém total controle.

No âmbito federal, há alguns programas desenvolvidos por órgãos do Poder Executivo e pelo Conselho Nacional de Justiça dignos de registro. O Ministério da Justiça, pelo Departamento Penitenciário Nacional - DEPEN, tem desenvolvido desde 2012 o Programa de Capacitação Profissional e Implementação de Oficinas Permanentes (PROCAP) para a criação de oficinas de trabalho e de cursos de capacitação em estabelecimentos penais, visando à integração do preso no mercado de trabalho. As Unidades federadas formulam diagnósticos e os submetem à análise da União, que então efetua o repasse de recursos financeiros após a aprovação. No biênio 2012-2014, o Paraná teve 05 unidades prisionais beneficiadas com a criação de oficinas/cursos. ${ }^{40}$

O Poder Judiciário, pelo CNJ, desenvolve o Programa Começar de Novo instituído pela Resolução CNJ n 96/2009 e executado pelos Tribunais de Justiça, que "visa à sensibilização de órgãos públicos e da sociedade civil para que forneçam postos de trabalho e cursos de capacitação profissional para presos e egressos do sistema carcerário". ${ }^{41} \mathrm{O} \mathrm{CNJ}$ concede o Selo Começar de Novo a empresas, órgãos e instituições que oferecem cursos de capacitação ou vagas de trabalho para apenados, nos termos da Portaria $n^{\circ} 49$, de 30 de março de 2010, do CNJ. O Paraná passou a incentivar ostensivamente o programa a partir de $2014 .{ }^{42}$ Trata-se, porém, de uma mera premiação honorífica por um esforço cívico - não há benefício econômico pela adesão ao programa.

Além do Começar de Novo, o CNJ promove o programa Cidadania nos Presídios para a solução do problema de superlotação e valorização dos direitos de condenados, que em agosto de 2016 recebeu a adesão do Paraná, após o projeto piloto no Espírito Santo. ${ }^{43}$ Entre as iniciativas, consta a criação de "escritórios sociais, locais onde os presos encontrarão apoio psicossocial e profissional após o término de cumprimento de suas penas". ${ }^{44}$ No dia 18 de janeiro deste ano de 2017, o Supremo Tribunal Federal anunciou tratativas com o Ministério do Trabalho para a criação de um convênio, dentro do programa Começar de Novo, em que serão investido R \$ 30 milhões de recursos da União na qualificação de 15 mil apenados. ${ }^{45}$

Dos Poderes, o Legislativo parece ser o menos envolvido na questão da aproximação entre cárcere e comunidade pelo emprego. Identificam-se alguns projetos em trâmite no Congresso Nacional - sem pretensão de esgotar as iniciativas existentes -, como o Projeto de Lei 1.506/15, que prevê incentivos fiscais e preferência em licitações públicas às iniciativas 
de inclusão social para detentos, com a cessão de selos para empresas e órgãos que ofertarem vagas (a proposta encontra-se sob análise da Comissão de Constituição e Justiça e Cidadania). ${ }^{46}$ Há, também, o Projeto 470/2011, mais antigo, que propõe a alteração da Lei ${ }^{\circ}$ 7.210/84 e prevê, por exemplo, a redução ou a não incidência de contribuições sociais pelo tempo em que perdurar a contratação e a reserva de vagas pela administração pública federal, estadual e municipal, ao fazer a contratação de mão de obra terceirizada (esse projeto também está igualmente em trâmite). ${ }^{47}$

No Paraná, há, por exemplo, a proposta de no 323/2015 em trâmite na Assembleia Legislativa para a concessão de subvenção econômica às empresas que contratarem egressos ou apenados em regime aberto e semiaberto do sistema prisional do Paraná, ou condenados em cumprimento de prisão domiciliar. A subvenção deverá ser repassada trimestralmente, mediante assinatura de termo de compromisso, no valor correspondente a dois salários mínimos por mês para cada contratado. ${ }^{48}$

A criação de programas de facilitação do acesso de presidiários ao mercado de trabalho atende àquilo que Dotti define como "processo de diálogo" entre o condenado e o Estado, que tem relação com a abertura de "canais de aproximação" entre a comunidade de um lado e o condenado de outro. É expressão de um sistema penal legitimamente social e democrático a lógica segundo a qual a "perda da liberdade, por ser temporária, somente interrompe a fruição de alguns direitos, além de não extinguir os que não foram alcançados pela condenação". É por isso que a "garantia real destes direitos e a perspectiva de recuperação dos outros deve ser a base dogmática de uma execução penal orientada finalisticamente", conforme assinala Dotti. ${ }^{49}$

Ocorre, no entanto, que a efetividade das indispensáveis políticas públicas relacionadas ao trabalho do preso - "execução penal orientada finalísticamente" -, dependem das oportunidades levadas à efeito pelo setor privado, responsável pela produção de bens e serviços numa ordem capitalista.

\section{A FUNÇÃO SOCIAL DA EMPRESA VOLADA À REINSERÇÃO DO APENADO}

É consabida a dificuldade de presos e de egressos obterem emprego, pelos mais diversos motivos, desde o preconceito até a desqualificação para o trabalho cultivada ao longo do cumprimento ocioso da condenação. O Estado deve envidar todos os esforços possíveis no 
sentido de ressocializar condenados, a fim de evitar que voltem a praticar crimes. Trata-se, porém, de uma tarefa difícil, considerando os conhecidos fatores criminógenos relacionados à privação de liberdade, sem se olvidar da influência negativa das facções criminosas nas prisões brasileiras, violadora de direitos fundamentais.

Ao tempo da realização da pesquisa de dados destinados à elaboração deste artigo, liam-se nos jornais notícias estarrecedoras de chacinas bestiais ocorridas em Manaus/AM, no primeiro dia de 2017, em que 56 detentos do Complexo Penitenciário Anísio Jobim (COMPAJ) foram assinados por outros presos e, quatro dias após, em Boa Vista/RR, quando 33 presos foram mortos na Penitenciária Agrícola de Monte Cristo - PAMC, fruto de disputas entre facções criminosas rivais. ${ }^{50}$ No dia 15 de janeiro deste ano, não por acaso, informava-se o massacre mais violento ocorrido no Rio Grande do Norte, na Penitenciária Estadual de Alcaçuz (região metropolitana de Natal), pela morte de pelo menos 26 pessoas carbonizadas, esquartejadas ou decapitadas por facções rivais. ${ }^{51}$

Negi Calixto ponderava, já na década de 70, o problema do convívio em comum entre delinquentes com periculosidades distintas e a situação dos presídios que funcionam como trincheiras de grupos criminosos, pontuando que "a superlotação das prisões, no Brasil, vem provocando, pela indiscriminação com que vários tipos de delinquentes são tratados, o contágio dos recuperáveis, por contato com a minoria realmente perigosa"52. O autor vaticinara, então, que "a tendência moderna, e não se esconde isso, é substituir a privação da liberdade por um regime de trabalho socialmente reajustador, que ofereça as condições da existência livre ou dela se aproxime". ${ }^{53}$ Ao que completou: "o trabalho presidiário ultrapassa os limites do benefício para destacar-se como um direito, um dever, sob a égide do sentido educativo-regenerativo". 54

Ocorre que somente o Estado não poderia dar conta desse desiderato. Considerando a dimensão sociológica do problema penitenciário e que o ideal de ressocialização não seria alcançável com a indiferença do corpo social, o artigo $4^{\circ}$, da LEP, prevê a "cooperação da comunidade nas atividades de execução da pena".

Ao tratar do papel da participação da sociedade na mudança do cenário prisional dantesco, Dotti ressalta que a "participação da comunidade nas questões de Direito Penal jamais poderia se caracterizar pela mera possibilidade, formalmente tolerada, mas pela probabilidade real de atuação junto aos poderes decisórios". ${ }^{55}$ Juan-Ramón Capella sustenta que o caráter libertário do novo Direito Penal depende da "remissão contínua para a 
articulação sociedade civil. Esta organiza-se para dar cumprimento a funções que lhe eram anteriormente estranhas". E acrescenta:

O novo tipo de direito não pode apoiar-se simplesmente na "sociedade". Exige uma
sociedade civil organizada, articulada em tono de centros da própria relação social e,
sobretudo, produtiva: organização da fábrica, da empresa, da comunidade
camponesa, dos trabalhadores científicos, dos centros de estudo, do bairro, da
juventude. ${ }^{56}$

A empresa assume, então, papel indispensável na modificação da realidade prisional e dos índices de violência. Leciona Bertoncini que por ser a empresa "expressão do direito de propriedade", o exercício de atividade econômica depende do cumprimento de sua função social. ${ }^{57}$ Com a superação do modelo liberal, a propriedade "se torna socialmente funcionalizada, de modo que sua atividade passa a ser relacionada também com o bem-estar da comunidade" 58 . Sob a égide do Estado Social, portanto, não há propriedade legítima que não cumpra com sua função social. Conforme F. C. Oliveira, o direito de propriedade sofreu restrições ao longo do século XX, "de forma a harmonizar os interesses do proprietário e os interesses sociais dos não-proprietários". Nas palavras do autor, houve uma "adaptação do exercício dos poderes proprietários a uma realidade social e econômica com menos ênfase individualista, ainda que orientada pelos valores do liberalismo econômico". 59 Igualmente, Bertoncini e Oikawa defendem que a propriedade se torna "socialmente funcionalizada" com o advento do Estado Social, para visar também ao bem-estar da comunidade. ${ }^{60}$

Com efeito, a Constituição de 1988, no Título da Ordem Econômica e Financeira, ao definir os Princípios Gerais da Atividade Econômica, estabelece que a "ordem econômica, fundada na valorização do trabalho humano e na livre iniciativa, tem por fim assegura a todos existência digna, conforme os ditames da justiça social" (art. 170). Para além dos princípios da valorização do trabalho humano e da livre iniciativa, há outros igualmente relevantes, dentre os quais se destaca, para os fins dessa pesquisa, o da função social da propriedade.

Portanto, pela função social da empresa, como consectário do princípio constitucional da função social da propriedade, busca-se estender ao particular tarefas imanentes ao Estado Social, como a redução de desigualdades e a construção de uma sociedade livre, justa e solidária. Segundo Bertoncini, "na busca da dignidade humana e da justiça social, todos os ramos de atuação empresarial são alcançados pela ideia de funcionalização", 61 
Destaca-se, também, o princípio constitucional da valorização do trabalho humano, assegurado a todos, norma que deve animar o olhar do empresário relativamente aos presos e egressos, quebrando-se o atual e preconceituoso paradigma. No entanto, não se deve perder de vista o fato de que a empresa não pode simplesmente ser instada a conceder empregos à população carcerária sem qualquer contrapartida, pois incumbe ao Estado a aplicação e a execução da pena. Em outras palavras, não pode haver uma pura e simples transferência de encargos do setor público para o setor privado, sob pena, inclusive, de inviabilizar este último, porquanto sujeito à livre concorrência.

Nessa perspectiva, cabe ao Estado incentivar a empresa por meio de sanções positivas, consoante explica Bobbio: "A noção de sanção positiva deduz-se, a contrario sensu, daquela mais bem elaborada de sanção negativa. Enquanto o castigo é uma reação a uma ação má, o prêmio é uma reação a uma boa ação". 62

À assunção pela empresa de sua função social na seara da valorização do trabalho humano, acolhendo a população carcerária, deve corresponder a uma atuação do Estado que não apenas garanta a segurança na ambiência do trabalho, mas que também estimule o setor privado a contratar essas pessoas, treiná-las para o trabalho e pagá-las condignamente. Como leciona Bobbio,

(...), a partir do momento em que, devido às exigências do Estado assistencial contemporâneo, o direito não mais se limita a tutelar atos conformes às próprias normas, mas tende a estimular atos inovadores - e, portanto, a sua função não é mais apenas protetora, mas também promocional -, surge, paralelamente ao emprego das sanções negativas, as quais constituem a técnica específica da repressão, um emprego, não importa se ainda limitado, de sanções positivas, que dão vida a uma técnica de estímulo e propulsão a atos considerados socialmente úteis, em lugar da repressão de atos considerados socialmente nocivos. ${ }^{63}$

Portanto, a equação de uma parcela do problema carcerário, passa pela criação de políticas públicas, como as noticiadas no item anterior, que fomentem a atuação do setor privado no treinamento de pessoas em conflito com a lei, visando a com elas contribuir no sentido de reabilitá-las e prepará-las para uma vida digna. Ganha o preso, que se habilita a uma vida independente e distante do crime; a empresa, que recebe incentivos estatais para o desempenho da atividade e passa a contar com um trabalhador capacitado; e a sociedade, que ao valorizar o preso, o desencoraja à reincidência, elevando o nível coletivo de segurança da comunidade.

Além do viés jurídico-normativo decorrente do modelo de Estado preconizado na Constituição (Social), a responsabilidade social da atividade empresarial pode ainda derivar 
de um princípio ético, na esteira da paradigmática formulação de Hans Jonas relacionada à proteção do meio ambiente contra a técnica moderna predatória. Partilhando da premissa de Jonas de que a perspectiva de um futuro pouco promissor autoriza a adoção de um comportamento ético renovado no presente, já que "o saber se origina daquilo contra o que devemos nos proteger" e que "malum imaginado deve aqui assumir o papel do malum experimentado",64, cabe cogitar da pertinência da formulação de um dever ético de solidariedade, a exigir da sociedade - e especialmente da empresa - uma atuação positiva com vistas a mudar a desumana realidade do cárcere. Ou seja, já não seria mais suficiente exigir que apenas o Estado concretize o que a história nacional tem demonstrado ser ele incapaz de fazê-lo (um cárcere condizente com o primado da dignidade da pessoa humana); a coletividade deve partilhar de uma responsabilidade que lhe interessa diretamente.

\section{CONSIDERAÇÕES FINAIS}

O desenvolvimento de programas de inclusão de condenados - especialmente custodiados - no mercado de trabalho com a oferta de postos de trabalho e cursos profissionalizantes é fundamental, convindo a criação de leis, no âmbito federal e estadual, que instituam benefícios às empresas que possam acelerar o processo de readaptação social e aprimoramento cívico de apenados e egressos do sistema carcerário brasileiro. A superlotação, o ambiente moralmente promíscuo e fértil a comportamentos desviantes, as condições indignas e degradantes dos estabelecimentos prisionais e a falta de perspectiva de uma ocupação honesta alimentam o caos histórico dos presídios brasileiros, que perpetuam a barbárie da qual a civilização pretende se ver livre.

Há iniciativas postas em andamento, mas é preciso mais. O trabalho é forma de resgate da dignidade da pessoa do preso, pois evita e ócio e pode servir de contraponto ao assédio das forças iníquas que dominam o ambiente carcerário. É inadmissível que o sistema prisional seja eterno sinônimo de embrutecimento e desumanização.

O projeto constitucional de desenvolvimento de uma sociedade livre, justa, solidária e fraterna depende da superação da lógica segundo a qual o tratamento de presos com humanidade constitui privilégio. A perspectiva de diminuição dos índices de violência, de aumento da produtividade e da arrecadação com a criação de postos formais pelo setor privado são elementos adicionais em prol da expansão e concretização do direito ao trabalho 
do presidiário, cuja fundamentalidade deriva do princípio constitucional da valorização do trabalho humano. Sua implementação interessa ao preso, que se habilita a uma vida independente e distante do crime; à empresa, que recebe incentivos estatais para o desempenho da atividade, por intermédio de políticas públicas que empreguem a técnica de sanções positivas; e à sociedade que, ao valorizar o preso, o desencoraja à reincidência, elevando o nível coletivo de segurança da comunidade.

Como afirmado na introdução, a resposta apresentada ao problema da pesquisa não é panaceia para a equação do problema carcerário brasileiro, cuja complexidade produz uma multiplicidade de problemas que ultrapassam os limites dessa pesquisa.

\section{REFERÊNCIAS}

BERTONCINI, Mateus. A função da empresa na implementação dos direitos da criança e do adolescente: globalização e trabalho infantil. Curitiba: Instituto Memória, 2014.

; Mateus; OIKAWA, Mariana. O Consumo consciente e a educação para o consumo como função social da empresa. Revista Jurídica - UNICURITIBA. v. 4, n. 33 (2013). ISSN: 2316-753X.

BOBBIO, Norberto. Da estrutura à função: novos estudos de teoria do direito; tradução de Daniela Beccaccia Versiane; revisão de Orlando Seixas Bechara, Renata Nagamine. Barueri, SP, 2007.

BRASIL. ASSEMBLÉIA LEGISLATIVA DO PARANÁ. Disponível em: $<$ http://www.alep.pr.gov.br/sala_de_imprensa/noticias/nereu-moura-propoe-incentivo-aempresa-que-contratar-egressos-ou-apenados-1>. Acesso em 11.01.2017.

BRASIL. CÂMARA DOS DEPUTADOS. Disponível em: <http://www2.camara.leg.br/legin/fed/lei/1980-1987/lei-7210-11-julho-1984-356938exposicaodemotivos-149285-pl.html>. Acesso em 06.01.2017.

BRASIL. CÂMARA DOS DEPUTADOS. Disponível em: <http://www.camara.gov.br/proposicoesWeb/fichadetramitacao?idProposicao=492369>. Acesso em 11.01.2017.

BRASIL. CÂMARA DOS DEPUTADOS. Disponível em: $<$ http://www.camara.gov.br/proposicoesWeb/fichadetramitacao?idProposicao=1247434>. Acesso em 11.01.2017.

BRASIL. CONSELHO NACIONAL DE JUSTIÇA. Cidadania nos Presídios. Disponível em: $<$ http://www.cnj.jus.br/sistema-carcerario-e-execucao-penal/cidadania-nos-presidios >. Acesso em: 05.01.2017. 
BRASIL. CONSELHO NACIONAL DE JUSTIÇA. Disponível em: $\langle$ http://www.cnj.jus.br/images/imprensa/diagnostico_de_pessoas_presas_correcao.pdf $>$. Acesso em 05.01.2017.

BRASIL. CONSELHO NACIONAL DE JUSTIÇA. Disponível em: $<$ http://www.cnj.jus.br/sistema-carcerario-e-execucao-penal/pj-mutirao-carcerario $>$. Acesso em 05.01.2017.

BRASIL. CONSELHO NACIONAL DE JUSTIÇA. Disponível em: $<$ http://www.cnj.jus.br/sistema-carcerario-e-execucao-penal/pj-mutirao-carcerario $>$. Acesso em 05.01.2017.

BRASIL. CONSELHO NACIONAL DE JUSTIÇA. Disponível em: $<$ http://www.cnj.jus.br/noticias/cnj/61599-insercao-de-presos-no-mercado-de-trabalhobeneficia-empresas-e-sociedade>. Acesso em 10.01.2017.

BRASIL. MINISTÉRIO DA JUSTIÇA. Disponível em: <http://www.justica.gov.br/seusdireitos/politica-penal/documentos/infopen_dez14.pdf> Acesso em 05.01.2017.

BRASIL. Supremo Tribunal Federal. EP 2 TrabExt-AgR/DF, Tribunal Pleno, Rel. Min. Roberto Barroso, julgado em 25.6.2014.

BRASIL. Superior Tribunal de Justiça. $3^{a}$ Seção. Súmula 562. Aprovada em 24/02/2016. DJe 29/02/2016.

BRASIL. Superior Tribunal de Justiça. REsp 1.381.315-RJ, Rel. Min. Rogerio Schietti Cruz, Terceira Seção, julgado em 13/5/2015, DJe 19/5/2015.

CAPELLA, Juan-Ramón. Sobre a extinção do direito e a supressão dos juristas. Trad. Maria Luzia Guerreiro. Coimbra: Centelha, 1977.

CALIXTO, Negi. Trabalho externo particular do condenado na execução penal. Revista dos Tribunais, São Paulo, v. 492, p. 423-432, out. 1976.

COMPARATO, Fábio Konder. A afirmação histórica dos direitos humanos. São Paulo: Saraiva, 2010.

DOTTI, René Ariel. Bases e alternativas para o sistema de penas. São Paulo: Revista dos Tribunais, 1998.

FRAGOSO, Heleno Cláudio. Ciência e experiência do direito penal. In: Revista Themis n. 2. Curitiba: Centro Acadêmico Hugo Simas, 1979. 
GOMES, Isabella Monteiro; SANTOS, Michel Carlos Rocha. Trabalho do preso: premissas para o reconhecimento dos direitos trabalhistas e da relação de emprego. Revista de Direito do Trabalho, São Paulo, v. 144, p. 193-210, out-dez 2011.

JONAS, Hans. O princípio responsabilidade: ensaio de uma ética para a civilização tecnológica; tradução do original em alemão Marijane Lisboa, Luiz Barros Montez. Rio de Janeiro: Contraponto: Ed. PUC-Rio, 2006.

LEITÃO, Leslie. Chegou a conta da barbárie. Revista Veja, São Paulo, 2512, ano 50/nº 2, p. 48-49, jan. 2017.

MIRABETE, Julio Fabbrini. Execução penal: comentários à Lei no 7.210, de 11-7-1984. 11 ed. São Paulo: Atlas, 2007.

MIR PUIG, Santiago. Introdución a las bases del derecho penal. Barcelona: Bosch, 1976.

OLIVEIRA, Francisco Cardozo. Uma nova racionalidade administrativa empresarial. In: GEVAERD, Jair \& TONIN, Marta Marília. Direito empresarial \& cidadania: questões contemporâneas. Curitiba: Juruá, 2006.

OLIVEIRA, Francisco Cardozo; RIBAS, Osni de Jesus Taborda. Possibilidade de ressocialização e evolução social: a valorização do trabalho do preso e acesso a posições proprietárias. Revista Jurídica - UNICURITIBA. v. 1, n. 30 (2013). ISSN: 2316-753X.

REALE JÚNIOR, Miguel. Instituições de direito penal. Rio de Janeiro: Forense, 2009.

VEJA ONLINE. Disponível em: <http://veja.abril.com.br/brasil/lideres-da-rebeliao-no-rnsao-ligados-ao-pcc/>. Acesso em 18.01.2017.

VEJA ONLINE. Disponível em: <http://veja.abril.com.br/brasil/massacre-de-presos-em-rr-eo-terceiro-maior-da-historia-do-pais/>. Acesso em 18.01.2017.

\footnotetext{
${ }^{1}$ LEITÃO, Leslie. Chegou a conta da barbárie. Revista Veja, São Paulo, 2512, ano 50/nº 2, p. 48-49, jan. 2017. p. 48.

2 Disponível em: 〈http://www.planalto.gov.br/ccivil_03/constituicao/constituicao24.htm〉. Acesso em 05.01.2017.

${ }^{3}$ Disponível em: 〈http://www.cnj.jus.br/sistema-carcerario-e-execucao-penal/cidadania-nos-presidios〉. Acesso em 05.01.2017.

4 Disponível em: <http://www.justica.gov.br/seus-direitos/politica-penal/documentos/infopen_dez14.pdf〉. Acesso em 05.01.2017.

5 Disponível em: 〈http://www.cnj.jus.br/images/imprensa/diagnostico_de_pessoas_presas_correcao.pdf>. Acesso em 05.01.2017.

${ }^{6}$ Disponível em: 〈http://www.cnj.jus.br/sistema-carcerario-e-execucao-penal/cidadania-nos-presidios〉. Acesso em 05.01.2017.

7 Disponível em: <http://www.justica.gov.br/seus-direitos/politica-penal/documentos/infopen_dez14.pdf>. Acesso em 05.01.2017.
} 
${ }^{8}$ Disponível em: 〈http://www.cnj.jus.br/sistema-carcerario-e-execucao-penal/cidadania-nos-presidios〉. Acesso em 05.01.2017.

${ }^{9}$ Disponível em: <http://www.cnj.jus.br/sistema-carcerario-e-execucao-penal/pj-mutirao-carcerario $>$. Acesso em 05.01.2017.

10 Disponível em: <http://www.cnj.jus.br/images/pesquisas-judiciarias/Publicacoes/mutirao_carcerario.pdf>. Acesso em 05.01.2017.

${ }^{11}$ Id., 2017, p. 169.

${ }^{12}$ Id., 2017, p. 169.

${ }^{13}$ Disponível em: <http://www.cnj.jus.br/images/pesquisas-judiciarias/Publicacoes/mutirao_carcerario.pdf>. p. 9. Acesso em 05.01.2017.

${ }^{14}$ DOTTI, René Ariel. Bases e alternativas para o sistema de penas. São Paulo: Revista dos Tribunais, 1998. p. 113.

${ }^{15}$ Id., 1998, p. 113.

${ }^{16}$ Id., 1998, p. 113.

${ }^{17}$ FRAGOSO, Heleno Cláudio. Ciência e experiência do direito penal. In: Revista Themis n. 2. Curitiba: Centro Acadêmico Hugo Simas, 1979. p. 78.

18 Disponível em: <http://www2.camara.leg.br/legin/fed/lei/1980-1987/lei-7210-11-julho-1984-356938exposicaodemotivos-149285-pl.html>. Acesso em 06.01.2017.

19 Disponível em: <http://www.crpsp.org.br/interjustica/pdfs/regras-minimas-para-tratamento-dos-presos-nobrasil.pdf>. Acesso em 06.01.2017.

Disponível em:

<http://www.cnj.jus.br/files/conteudo/arquivo/2016/05/39ae8bd2085fdbc4a1b02fa6e3944ba2.pdf>. Acesso em 06.01.2017.

${ }^{21}$ COMPARATO, Fábio Konder. A afirmação histórica dos direitos humanos. São Paulo: Saraiva, 2010. p. 72.

${ }^{22}$ OLIVEIRA, Francisco Cardozo; RIBAS, Osni de Jesus Taborda. Possibilidade de ressocialização e evolução social: a valorização do trabalho do preso e acesso a posições proprietárias. Revista Jurídica UNICURITIBA. v. 1, n. 30 (2013). ISSN: 2316-753X.

${ }_{23}$ Disponível em: <http://www2.camara.leg.br/legin/fed/lei/1980-1987/lei-7210-11-julho-1984-356938exposicaodemotivos-149285-pl.html>. Acesso em 06.01.2017.

${ }^{24}$ MIR PUIG, Santiago. Introdución a las bases del derecho penal. Barcelona: Bosch, 1976. p. 85-86.

${ }^{25}$ REALE JÚNIOR, Miguel. Instituições de direito penal. Rio de Janeiro: Forense, 2009. p. 339.

${ }^{26}$ Id., 2009, p. 339.

${ }^{27}$ BRASIL. Supremo Tribunal Federal. EP 2 TrabExt-AgR/DF, Tribunal Pleno, Rel. Min. Roberto Barroso, julgado em 25.6.2014.

28 Disponível em: <http://www.cnj.jus.br/noticias/cnj/61599-insercao-de-presos-no-mercado-de-trabalhobeneficia-empresas-e-sociedade>. Acesso em 10.01.2017.

${ }^{29}$ GOMES, Isabella Monteiro; SANTOS, Michel Carlos Rocha. Trabalho do preso: premissas para o reconhecimento dos direitos trabalhistas e da relação de emprego. Revista de Direito do Trabalho, São Paulo, v. 144, p. 193-210, out-dez 2011.

30 Disponível em: <http://www.justica.gov.br/seus-direitos/politica-penal/documentos/infopen_dez14.pdf>. Acesso em 06.01.2017.

31 Disponível em: <http://www.justica.gov.br/seus-direitos/politica-penal/documentos/infopen_dez14.pdf>. Acesso em 06.01.2017.

32 Disponível em: <http://www.justica.gov.br/seus-direitos/politica-penal/cnpcp-1/imagens-cnpcp/planonacional-de-politica-criminal-e-penitenciaria-2015.pdf>. p. 25-26. Acesso em 09.01.2017.

${ }^{33}$ Ibid.

${ }^{34}$ Ibid., p. 26 e 33.

${ }^{35}$ BRASIL. Supremo Tribunal Federal. EP 2 TrabExt-AgR/DF, Tribunal Pleno, Rel. Min. Roberto Barroso, julgado em 25.6.2014.

${ }^{36}$ BRASIL. Superior Tribunal de Justiça. $3^{\text {a }}$ Seção. Súmula 562. Aprovada em 24/02/2016. DJe 29/02/2016.

${ }^{37}$ BRASIL. Superior Tribunal de Justiça. REsp 1.381.315-RJ, Rel. Min. Rogerio Schietti Cruz, Terceira Seção, julgado em 13/5/2015, DJe 19/5/2015.

${ }_{38}$ MIRABETE, Julio Fabbrini. Execução penal: comentários à Lei no 7.210, de 11-7-1984. 11 ed. São Paulo: Atlas, 2007. p. 107.

${ }^{39}$ Ibid., p. 107. 
40 Disponível em: <http://www.justica.gov.br/seus-direitos/politica-penal/politicas-2/trabalho-e-renda-nosistema-prisional/acoes-de-trabalho-nas-prisoes $>$. Acesso em 11.01.2017.

41 Disponível em: < http://www.cnj.jus.br/sistema-carcerario-e-execucao-penal/pj-comecar-de-novo>. Acesso em 11.01.2017.

${ }^{42}$ Disponível em: <http://www.cnj.jus.br/noticias/cnj/28611-patronatos-penitenciarios-do-parana-vao-implantaro-programa-comecar-de-novo $>$. Acesso em 11.01.2017.

${ }_{43}$ Disponível em: <http://www.cnj.jus.br/noticias/cnj/83327-tribunal-de-justica-do-parana-adota-programacidadania-nos-presidios>. Acesso em 11.01.2017.

44 Ibid.

45 Disponível em: <http://www.stf.jus.br/portal/cms/verNoticiaDetalhe.asp?idConteudo=334106>. Acesso em 19.01.2017.

46 Disponível em: <http://www.camara.gov.br/proposicoesWeb/fichadetramitacao?idProposicao=1247434>. Acesso em 11.01.2017.

47 Disponível em: <http://www.camara.gov.br/proposicoesWeb/fichadetramitacao?idProposicao=492369>. Acesso em 11.01.2017.

48 Disponível em: <http://www.alep.pr.gov.br/sala_de_imprensa/noticias/nereu-moura-propoe-incentivo-aempresa-que-contratar-egressos-ou-apenados-1>. Acesso em 11.01.2017.

${ }^{49}$ DOTTI, 1998. p. 142.

50 Disponível em: <http://veja.abril.com.br/brasil/massacre-de-presos-em-rr-e-o-terceiro-maior-da-historia-dopais/>. Acesso em 18.01.2017.

51 Disponível em: <http://veja.abril.com.br/brasil/lideres-da-rebeliao-no-rn-sao-ligados-ao-pcc/>. Acesso em 18.01.2017.

${ }^{52}$ CALIXTO, Negi. Trabalho externo particular do condenado na execução penal. Revista dos Tribunais, São Paulo, v. 492, p. 423-432, out. 1976. p. 426.

${ }^{53}$ Ibid., p. 426.

${ }^{54}$ Ibid., p. 428.

55 DOTTI, 1998. p. 134.

56 CAPELLA, Juan-Ramón. Sobre a extinção do direito e a supressão dos juristas. Trad. Maria Luzia Guerreiro. Coimbra: Centelha, 1977. p. 99.

${ }^{57}$ BERTONCINI, Mateus. A função da empresa na implementação dos direitos da criança e do adolescente: globalização e trabalho infantil. Curitiba: Instituto Memória, 2014. p. 50.

${ }^{58}$ Ibid., p. 51.

${ }^{59}$ OLIVEIRA, Francisco Cardozo. Uma nova racionalidade administrativa empresarial. In: GEVAERD, Jair \& TONIN, Marta Marília. Direito empresarial \& cidadania: questões contemporâneas. Curitiba: Juruá, 2006. p. $110-111$.

${ }^{60}$ BERTONCINI; Mateus; OIKAWA, Mariana. O Consumo consciente e a educação para o consumo como função social da empresa. Revista Jurídica - UNICURITIBA. v. 4, n. 33 (2013). ISSN: 2316-753X.

${ }_{61}^{61}$ BERTONCINI, op. cit., p. 57.

${ }^{62}$ BOBBIO, Norberto. Da estrutura à função: novos estudos de teoria do direito; tradução de Daniela Beccaccia Versiane; revisão de Orlando Seixas Bechara, Renata Nagamine. Barueri, SP, 2007, p. 24.

${ }^{63}$ BOBBIO, op. cit., p. 24.

${ }^{64}$ JONAS, Hans. O princípio responsabilidade: ensaio de uma ética para a civilização tecnológica; tradução do original em alemão Marijane Lisboa, Luiz Barros Montez. Rio de Janeiro: Contraponto: Ed. PUC-Rio, 2006. p. 71-72. 